\title{
Wardrobe Malfunctions and the Measurement of Internet Behaviour $^{*}$
}

\author{
Roland Pfister \\ Department of Psychology III, Julius-Maximilians-University of Würzburg, Würzburg, Germany. \\ Email: roland.pfister@psychologie.uni-wuerzburg.de \\ Received January $4^{\text {th }}$, 2011; revised February 24 ${ }^{\text {th }}, 2011$; accepted April $10^{\text {th }}, 2011$.
}

\begin{abstract}
The wardrobe malfunction — an unanticipated exposure of bodily parts in the public — has become a prevailing issue in concerts, shows and other celebrity events that is reliably reported by the media. The internet as the fastest source for celebrity gossip allows measuring the impact of such wardrobe malfunctions on the public interest in a celebrity. This measurement in turn allows conclusions about intention, motivation, and internet behaviour of a wide variety of internet users. The present study exemplifies the use of an innovative non-reactive measure of active interest- the Search Volume Index-to assess the impact of a variety of internet-related phenomena, including wardrobe malfunctions. Results indicate that interest in a celebrity increases immediately after such an event and stays at a high level for about three weeks (the wardrobe plateau). This special form of celebrity gossip thus meets a constant interest of a substantial proportion of internet users.
\end{abstract}

Keywords: Internet Behaviour, Search Volume Index, Non-reactive Measurement, Wardrobe Malfunction

\section{Introduction}

January 31, 2004, gave rise to an intense public discussion as the right breast cup of Janet Jackson's costume was torn off during the Super Bowl live event that was broadcasted on American and international television. The event was instantly reported in numerous television shows, print media, and the internet where discourse centered primarily on the intentionality of the incident (Holland, 2009). This discourse eventually led to the creation of a term that was nearly awarded word of the year 2004: the wardrobe malfunction (American Dialect Society, 2005).

A wardrobe malfunction was defined as an "unanticipated exposure of bodily parts" by the American Dialect Society (2005) or, in more detail, as "an accidental or supposedly accidental failure of clothing to cover parts of the body intended to be covered" (Peckham, 2005). Such wardrobe malfunctions occurred frequently ever since the 2004 Super Bowl show and were reliably reported in the media, especially the internet which has become the most important portal for celebrity news (Choi \& Berger, 2010). Thus, wardrobe malfunctions seem to be one of several ways to increase internet presence which in turn helps to maintain celebrity status (Gamson, 2002; Kurzman et al., 2007).

This speculation, however, only holds true if such news are of interest to a broader mass of people. Several recent studies assessed the characteristics of people who are interested in celebrity gossip, and, among others, correlations were found with addiction (Sheridan, North, Matlby, \& Gillett, 2007) and sensation seeking (McCutcheon, Ashe, Houran, \& Maltby, 2003). Further studies exploring motivations of internet users in general discovered a profound contribution of social as well as

*This publication was funded by the German Research Foundation (DFG) and the University of Würzburg in the funding programme Open Access Publishing. sexual motives, including recent internet-related pathologies such as cyberstalking or addiction to cybersex (Young, Pistner, O’Mara, \& Buchanan, 1999).

In the light of the findings on individual motives of internet users, celebrity misbehaviours such as wardrobe malfunctions could indeed provide a powerful tool to boost a celebrities' web presence. This hypothesis was tested empirically by using the novel, non-reactive measure of Search Volume Indices, roughly corresponding to the global internet traffic being produced by Google searches for a given term.

\section{Method}

Seventeen wardrobe malfunctions from 2004 to 2009 were identified and included in the analysis (see Appendix for a complete list). This selection of cases concentrates on wardrobe malfunctions that occurred during official events and were observed by numerous people, such as TV shows, concerts, or film festivals. However, this collection is necessarily subjective as there are no comprehensive lists from serious sources available. The case of Janet Jackson described above was not used for further data analysis to avoid an overestimation of a wardrobe malfunction's impact due to the archetypical nature of the case and the extremely high media presence that followed it. For a comparison to the data of the remaining cases, the impact of Janet Jackson's wardrobe malfunction on the chosen dependent variable of Search Volume Indices is shown in Figure 1.

For each of the 17 cases identified, Search Volume Indices (SVIs) were assessed via Google Trends (Google Inc., 2009). The SVI quantifies the impact of a given keyword on global internet traffic as measured by the number of Google searches for that keyword. Thus, the SVI represents a non-reactive measure of active interest in a given topic. SVI scores are provided for each week since January 2004 and they are scaled relative to the mean traffic produced by the keyword in this first 


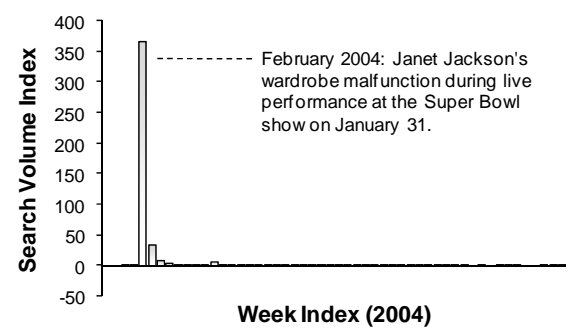

Figure 1.

Search Volume Indices (SVI) as a non-reactive, relative measure of internet traffic produced by Google searches for "Janet Jackson" in the course of 2004. SVIs can be interpreted as a week's traffic in relation to the average traffic during January 2004. The first week of February 2004-following Jackson's wardrobe malfunction during the Super Bowl show on January 31-thus yielded an increase of relative internet traffic by a factor of about 370 .

month (fixed scaling). Thus, a fictive SVI score for the term "Psychology" of 1.5 in the last week of August 2004 indicates that internet traffic produced by this term in this week is 1.5 times as much as during January 2004. Fixed SVIs were extracted for each of the four weeks prior to the event (being relatively constant at SVI = 1), for the week of the event, and for the following eight weeks.

\section{Results}

All scores were baseline-corrected by subtracting the mean SVI of the four weeks prior to the wardrobe malfunction. SVIs were averaged across all 17 cases and 99\% confidence intervals were computed for each week (see Figure 2). SVIs instantly increased in the week of the event and stayed at a constant level for the next week, too. In week three after the event, SVIs were markedly decreased but still significantly above baseline, marking the end of the wardrobe plateau. Finally, and being at a relatively low level already, SVIs started to decrease asymptotically in the following weeks (see Figure 2; details of the effects for each case of wardrobe malfunction are included in the Appendix).

For further statistical analysis, individual profiles were aggregated to four time markers: the time prior to the wardrobe malfunction (baseline), the week of the wardrobe malfunction, the week after the wardrobe malfunction, and the following 7 weeks. These four data points were analyzed by within-subjects ANOVA with the single factor of time. The factor's significant influence, $F(3,48)=3.73, p=.035, \eta_{\mathrm{p}}{ }^{2}=.19$ (GreenhouseGeisser adjusted to account for non-sphericity), was mainly based on a quadratic trend with timescale-corrected contrast vector, $F(1,16)=7.16, p=.016, \eta_{\mathrm{p}}{ }^{2}=.31$, without linear or cubic components (both $F$ 's $<1$ ).

\section{Discussion}

The impact of wardrobe malfunctions on a celebrity's internet presence was assessed by means of the internet traffic that was produced by Google searches for the name of the celebrity in question. Examining 17 cases of wardrobe malfunction, a statistically reliable increase of searches was found as long as the third week after the incident with a plateau activity during

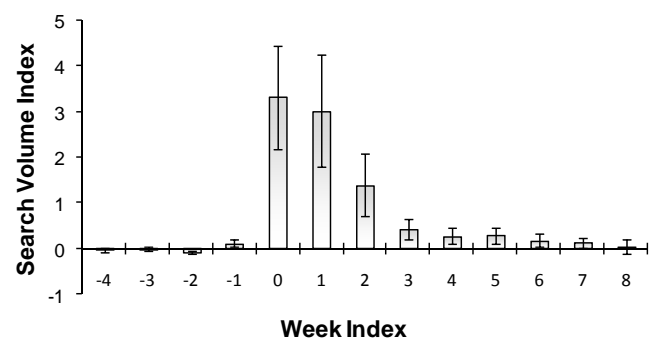

Figure 2.

Baseline-corrected mean SVI scores of 17 cases of wardrobe malfunction in relation to the onset of the event in week 0 . Error bars represent $99 \%$ confidence intervals.

the first two to three weeks. This plateau activity amounted to a baseline-corrected SVI of about 3, indicating a substantially increased internet presence during that time. Given the fast-paced nature of the internet community, the reported impact duration of about 3 weeks is even more remarkable and indicates a profound interest in this type of news among a high proportion of internet users. Even though no conclusions are possible about the interrelations with other factors, the motive of using the internet as a source for celebrity gossip in combination with soft pornographic material fits with other results on internet-related motives such as social and affective motives or interest in pornography (Young et al., 1999).

Considering the nature of SVIs as dependent variable, several alternative explanations might also account for the increased interest in a celebrity after a wardrobe malfunction. For instance, the present experiment only analyzed events that were broadcasted to numerous people. Thus, the increased interest might indicate solely an interest in the event as such. This alternative explanation was tested by further analyses that used a similar situation but without wardrobe malfunction and applied the same test as before (data not shown here). In these analyses, no comparable increase could be detected for any event. The increased internet presence of a celebrity after a wardrobe malfunction is thus indeed specific to the event studied.

Taken together, the present study demonstrated the use of Search Volume Indices as a non-reactive measure of internet behaviour. The measure provides an attractive opportunity for internet research as the data is readily available and provides a unique opportunity for studying internet behaviour on a broader scale. The method can easily be applied to a wide variety of research questions and might provide a valuable tool for media researchers.

\section{References}

American Dialect Society (2005). 2004 Words of the year final vote. URL (Retrieved 5 November 2009) http://www.americandialect.org /2004_Words_of_the_Year_Final_Vote.pdf

Choi, C. J., \& Berger, R. (2010). Ethics of celebrities and their increasing influence in 21st century society. Journal of Business Ethics, 91, 313-318. doi:10.1007/s10551-009-0090-4

Gamson, J. (2000). The web of celebrity. American Prospect, 11, 40-41.

Google Inc. (2009). About Google Trends. URL (Retrieved 25 October 2009) http://www.google.com/intl/en/trends/about.html\#7

Holland, S. L. (2009). The "offending" breast of Janet Jackson: Public discourse surrounding the Jackson/Timberlake performance at Super 
Bowl XXXVIII. Women's Studies in Communication, 32, 129-150.

Kurzman, C., Anderson, C., Key, C., Lee, Y. O., Moloney, M., \& Silver, A., et al. (2007). Celebrity status. Sociological Theory, 25, 347-367. doi:10.1111/j.1467-9558.2007.00313.x

McCutcheon, L. E., Ashe, D. D., Houran, J., \& Maltby, J. (2003). A cognitive profile of individuals who tend to worship celebrities. Journal of Psychology, 137, 309-322.

doi:10.1080/00223980309600616

Peckham, A. (2005). Urban dictionary: Fularious street slang defined.
Kansas City, MO: Andrews McMeel Publishing.

Sheridan, L., North, A., Maltby, J., \& Gillett, R. (2007). Celebrity worship, addiction and criminality. Psychology Crime \& Law, 13, 559-571. doi:10.1080/10683160601160653

Young, K., Pistner, M., O’Mara, J., \& Buchanan, J. (1999). Cyber disorders: The mental health concern for the new millenium. $C y$ berpsychology \& Behavior, 2, 475-479. doi:10.1089/cpb.1999.2.475

\section{Appendix}

Individual case statistics for all cases included in the present analysis. Numbers in the three effect columns represent SVI scores for the week of the event (Week 0) and the following two weeks (Week 1 and Week 2).

\begin{tabular}{|c|c|c|c|c|c|c|}
\hline \multirow{2}{*}{ Case } & \multirow{2}{*}{ Name } & \multicolumn{2}{|c|}{ Event } & \multicolumn{3}{|c|}{ Effect } \\
\hline & & Month & Year & Week 0 & Week 1 & Week 2 \\
\hline 1 & Pamela Anderson & March & 2009 & 0.10 & 0.02 & 0.00 \\
\hline 2 & Toni Braxton & June & 2006 & 1.09 & 0.01 & -0.34 \\
\hline 3 & Naomi Campbell & January & 2005 & 5.85 & 1.05 & 0.14 \\
\hline 4 & Katrina Campins & March & 2005 & 0.96 & 0.54 & 0.15 \\
\hline 5 & Mariah Carrey & July & 2005 & 2.72 & 0.4 & -0.16 \\
\hline 6 & Julie Ferrier & February & 2009 & 1.47 & 3.09 & -0.10 \\
\hline 7 & Jennifer Hawkins & August & 2004 & 4.65 & 3.57 & 0.20 \\
\hline 8 & Beyoncé Knowles & August & 2007 & 0.37 & 0.02 & -0.10 \\
\hline 9 & Lindsay Lohan & February & 2006 & 2.45 & 0.95 & 0.36 \\
\hline 10 & Sophie Marceau & May & 2005 & 22.95 & 8.75 & 0.26 \\
\hline 11 & Kate Moss & March & 2009 & 0.36 & 0.09 & 0.15 \\
\hline 12 & Eva Padberg & May & 2009 & 0.2 & 0.25 & 0.05 \\
\hline 13 & Gwyneth Paltrow & September & 2009 & -0.01 & -0.14 & -0.23 \\
\hline 14 & Natalie Portman & June & 2009 & -0.12 & -0.15 & -0.09 \\
\hline 15 & Tara Reid & October & 2004 & 3.85 & 23.65 & 4.14 \\
\hline 16 & Britney Spears & September & 2007 & 2.05 & 0.41 & 0.21 \\
\hline 17 & Emma Watson & July & 2009 & 7.3 & 8.70 & 2.04 \\
\hline
\end{tabular}

